\title{
Radiological Features of Brain Metastases from Non-small Cell Lung Cancer Harboring EGFR Mutation
}

\author{
SHINKICHI TAKAMORI ${ }^{1}$, GOUJI TOYOKAWA ${ }^{1}$, MOTOTSUGU SHIMOKAWA ${ }^{2}$, FUMIHIKO KINOSHITA ${ }^{1}$, \\ YUKA KOZUMA $^{1}$, TAICHI MATSUBARA ${ }^{1}$, NAOKI HARATAKE ${ }^{1}$, TAKAKI AKAMINE ${ }^{1}$, \\ NOBUTAKA MUKAE ${ }^{3}$, FUMIHIKO HIRAI ${ }^{1}$, TETSUZO TAGAWA ${ }^{1}$, YOSHINAO ODA ${ }^{4}$, \\ TORU IWAKI ${ }^{5}$, KOJI IIHARA ${ }^{3}$, HIROSHI HONDA $^{6}$ and YOSHIHIKO MAEHARA ${ }^{1}$ \\ Departments of ${ }^{1}$ Surgery and Science, ${ }^{3}$ Neurosurgery, ${ }^{4}$ Anatomic Pathology, and ${ }^{6}$ Radiology, and \\ ${ }^{5}$ Department of Neuropathology - Neurological Institute, \\ Graduate School of Medical Sciences, Kyushu University, Fukuoka, Japan; \\ ${ }^{2}$ Clinical Research Institute, National Kyushu Cancer Center, Fukuoka, Japan
}

\begin{abstract}
Aim: To investigate the radiological features on computed tomography (CT) of brain metastasis (BM) from epidermal growth factor receptor (EGFR)-mutated non-small cell lung cancer (NSCLC). Patients and Methods: Thirtyfour patients with NSCLC with BMs who underwent surgical resection of the BMs at the Department of Neurosurgery, Kyushu University from 2005 to 2016 were enrolled in the study. The EGFR statuses of the 34 BMs were investigated. Radiological features, including the number, size, and location of the tumor, were delineated by CT. Results: Patients with EGFR-mutated BMs had significantly higher frequencies of multiple metastases than those with the nonEGFR-mutated type ( $p=0.042)$. BMs harboring mutations in $E G F R$ were more frequently observed in the central area of the brain compared to those without mutations in EGFR ( $p=0.037)$. Conclusion: Careful follow-up of patients with EGFR-mutated NSCLC may be necessary given the high frequencies of multiple BMs and their location in the central area of the brain.
\end{abstract}

Lung cancer is one of the most lethal types of cancer worldwide (1), and non-small cell lung cancer (NSCLC) accounts for $85-90 \%$ of the disease (2). As a pharmacological therapy for NSCLC, chemotherapy has long been used for advanced NSCLC and in an adjuvant setting

Correspondence to: Tetsuzo Tagawa, Department of Surgery and Science, Graduate School of Medical Sciences, Kyushu University, Fukuoka 812-8582, Japan. Tel: +81 926425466, Fax: +81 926425482, e-mail: t_tagawa@surg2.med.kyushu-u.ac.jp

Key Words: Non-small cell lung cancer, computed tomography, brain metastasis, epidermal growth factor receptor, radiological feature.
(2). In the 2000s, tyrosine kinase inhibitors (TKIs) against several genes, including epidermal growth factor receptor $(E G F R)$ and anaplastic lymphoma kinase $(A L K)$, were approved for selected patients with NSCLC whose tumors had such gene mutations (2). Additionally, immunotherapy targeting programmed cell death-1 and programmed cell death-ligand 1 (PD-L1) has also become one of the standard pharmacological therapies in limited patients with NSCLC whose tumor cells expressed PD-L1 (3). Thus, it is important for clinicians to know the tumor characteristics before treatment in order to determine the therapeutic strategy for patients with NSCLC.

Recently, the relationship between radiological features delineated by computed tomography (CT) and tumor characteristics has been reported (4-6). Toyokawa et al. showed that PD-L1 expression of lung adenocarcinoma could be predicted by certain features of a tumor on CT, such as convergence and cavitation (6), and that lung adenocarcinoma adjoining emphysematous bullae was associated with invasive features of the tumor (5). With regard to the utility of radiological characteristics in detecting gene mutation status, Yamamoto et al. suggested that three CT features, namely central tumor location, large pleural effusion, and the absence of pleural tail, were useful in predicting the presence of ALK fusion gene (7). Hasegawa et al. reported that EGFR-mutated adenocarcinoma was associated with significantly higher frequencies of multiple bilateral lung metastases, convergence of surrounding structures, surrounding ground glass opacity and notch on $\mathrm{CT}$ in comparison to non-EGFR-mutated type (8). However, the radiological features of brain metastases (BM) from NSCLC harboring EGFR mutation has not been investigated. Thus, we aimed to elucidate the radiological characteristics of BM with mutations in EGFR in patients with NSCLC. 


\section{Patients and Methods}

Patients. From January 2005 to December 2016, 36 patients with NSCLC with BMs underwent surgical resection of BMs at the Department of Neurosurgery, Graduate School of Medical Sciences, Kyushu University (Fukuoka, Japan). Of 36 patients, two who were diagnosed as having small cell lung cancer were excluded. Thus, the remaining 34 patients were enrolled in the present study. A retrospective analysis was conducted of age, sex, smoking history (pack-years: PY), and performance status (PS). Pathological type of primary lung tumors and EGFR mutation status of the BMs were also analyzed. The EGFR mutation status of the primary lung cancer and their BMs were determined using the peptide nucleic acidlocked nucleic acid polymerase chain reaction clamp method (Mitsubishi Chemical Medience, Tokyo, Japan). Regarding radiological factors, the number, size, and location of the BMs were investigated. The Institutional Review Board of our Institution approved the current study (IRB No. 27-435).

Brain CT. Brain CT was performed with the patient in the supine position using a 64-detector-row CT scanner (Aquilion, Toshiba Medical Systems Corporation, Tochigi, Japan). All of the CT data were transferred to a Picture Archiving and Communication System which was accessible by the workstations (Volume Analyzer, SYNAPSE-VINCENT; Fujifilm, Tokyo, Japan) with a specialized application for the brain. One Author (S.T.) was blinded to the patients' clinical information including EGFR status of the BMs, and evaluated all the brain CT images.

Statistical analysis. The associations between EGFR mutation status of BMs and clinical or radiological factors were analyzed using Student's $t$-test, two-sided Fisher's exact test, and Mann-Whitney $U$-test where appropriate. The differences were considered to be statically significant when the $p$-values were less than 0.05. All of the statistical analyses were performed using the JMP ${ }^{\circledR} 13$ (SAS Institute Inc., Cary, NC, USA).

\section{Results}

Patient characteristics. Table I shows the characteristics of the patients included in this study. The median age was 64 (range=29-76) years, and $23(67.6 \%)$ were male. Twenty-five (73.5\%) were current or former smokers (median PY: 30; range: $0-84)$. The PS was 0 or 1 in $19(55.9 \%)$ patients. Thirty $(88.2 \%)$ and four $(11.8 \%)$ patients were pathologically diagnosed with adenocarcinoma and NSCLC, respectively. Sensitive EGFR mutations were detected in eight $(25.0 \%)$ patients in both primary lung tumors and their BMs, including L858R and 19 deletion in five (14.7\%) and three $(8.8 \%)$ patients, respectively. With regard to radiological features, multiple BMs were observed in 14 (41.2\%) patients. The mean size of each resected specimen was $3.6 \mathrm{~cm}$ (standard deviation=1.2 cm). The BMs were located in the supratentorial area in $29(85.3 \%)$ patients. Twenty-seven (79.4\%) patients had BMs in the cortico-medullary area.

Characteristics of patients with NSCLC with BMs harboring EGFR mutation. The clinical and radiological characteristics of patients with NSCLC with BMs with mutation in EGFR is shown in Table II. BMs harboring EGFR mutation were significantly associated with never-smoker patients with NSCLC $(p=0.001)$ and fewer PY $(p<0.001)$. The EGFR status of the BMs was consistent in all cases with that of the primary lung tumors. Regarding radiological features, EGFR-mutated BMs were associated with significantly higher frequencies of multiple metastases than non-EGFRmutated type $(p=0.042)$. The size of $\mathrm{BMs}$ and the frequencies of supratentorial BMs did not differ between in those with EGFR-mutated and those with non-EGFRmutated tumors ( $p=0.675$ and $p=0.309$, respectively). However, the BMs harboring mutations in EGFR were more frequently observed in the central area of the brain compared to those without EGFR mutations ( $p=0.037$ ).

\section{Discussion}

According to previous reports, approximately $8-10 \%$ of patients with cancer develop BMs (9, 10). Treatment modalities for BMs include surgery, radiation, medication, and best supportive care (11). Surgical resection is indicated mainly for, but not limited to, those BMs considered to be controllable, and when the symptoms derived from the BMs should be alleviated in terms of quality of life of the patients $(12,13)$. In the current study, most of the patients with BMs underwent surgery with the aim of reducing the severe symptoms. Thus, 34 patients with BMs were retrospectively analyzed. We demonstrated that the EGFR-mutated BMs were associated with significantly higher frequencies of multiple metastases and their location in the central area of the brain compared with the non-EGFR-mutated BMs. To the best of our knowledge, this is the first report on the association between EGFR status and CT features of BMs from NSCLC. Although the EGFR status of the BMs were all consistent with those of the primary lung tumors, we examined EGFR mutations of the samples from the BMs, not from the primary NSCLC, given the rare discordance in EGFR status between primary and metastatic NSCLC (14).

With regard to the presence of multiple metastases as a radiological characteristic of $E G F R$-mutated BMs, a previous retrospective study investigating 263 patients with primary lung adenocarcinoma suggested that EGFR-mutated lung adenocarcinoma was associated with a significantly higher frequency of multiple bilateral lung metastases in comparison to the non-EGFR-mutated type, which is consistent with our results (8). In addition, a previous review article analyzing more than 2000 Asian patients with refractory NSCLC indicated that the presence of multiple lung metastases was associated with improved response to gefitinib, regardless of the EGFR mutation status (15). Although we cannot discuss the response to EGFR-TKIs, because the patients who received such drugs were limited, future studies may 
Table I. Characteristics of patients with brain metastases (BMs) from non-small cell lung cancer (NSCLC) $(n=34)$.

\begin{tabular}{|c|c|}
\hline Factor & Value \\
\hline \multicolumn{2}{|l|}{ Clinicopathological } \\
\hline \multicolumn{2}{|l|}{ Age, years } \\
\hline Median & 64 \\
\hline Range & $29-76$ \\
\hline \multicolumn{2}{|l|}{ Gender, $\mathrm{n}$} \\
\hline Male & 23 \\
\hline Female & 11 \\
\hline \multicolumn{2}{|l|}{ Smoking history, $\mathrm{n}$} \\
\hline Never-smoker & 9 \\
\hline Smoker & 25 \\
\hline \multicolumn{2}{|l|}{ Pack-years } \\
\hline Median & 30 \\
\hline Range & $0-84$ \\
\hline \multicolumn{2}{|l|}{ Performance status, $\mathrm{n}$} \\
\hline$\leq 1$ & 19 \\
\hline$\geq 2$ & 15 \\
\hline \multicolumn{2}{|l|}{ Pathological type, $\mathrm{n}$} \\
\hline Adenocarcinoma & 30 \\
\hline NSCLC & 4 \\
\hline \multicolumn{2}{|c|}{$E G F R$ status of primary lung cancer, $\mathrm{n}$} \\
\hline Wild-type & 26 \\
\hline L858R & 5 \\
\hline 19 Deletion & 3 \\
\hline \multicolumn{2}{|c|}{$E G F R$ status of BMs, $\mathrm{n}$} \\
\hline Wild-type & 26 \\
\hline L858R & 5 \\
\hline 19 Deletion & 3 \\
\hline \multicolumn{2}{|l|}{ Radiological } \\
\hline \multicolumn{2}{|l|}{ Number of BMs, $n$} \\
\hline Single & 20 \\
\hline Multiple & 14 \\
\hline \multicolumn{2}{|l|}{ Size of the BMs, $\mathrm{cm}$} \\
\hline Mean (SD) & $3.6(1.2)$ \\
\hline \multicolumn{2}{|c|}{ Supratentorial $v s$. infratentorial, $\mathrm{n}$} \\
\hline Supratentorial & 29 \\
\hline Infratentorial & 5 \\
\hline \multicolumn{2}{|c|}{ Cortico-medullary $v s$. central, $\mathrm{n}$} \\
\hline Cortico-medullary & 27 \\
\hline Central & 7 \\
\hline
\end{tabular}

$E G F R$, Epidermal growth factor receptor; SD, standard deviation.

elucidate the relationship between the efficacy of EGFR-TKIs for BMs and their radiological features.

Our study also showed that the BMs harboring mutations in $E G F R$ were more frequently observed in the central area of the brain compared with those without such mutations. Within the brain, metastases are most commonly found in the cortico-medullary area due to the narrowing and acute angle branching of vessels (16-18). Thus, the EGFR-mutated BMs may be rare in terms of their location. Regarding the radiological characteristics of EGFR-mutated primary lung
Table II. Characteristics of patients with non-small cell lung cancer (NSCLC) with brain metastases (BMs) harboring an epidermal growth factor receptor (EGFR) mutation $(n=34)$.

\begin{tabular}{|c|c|c|c|}
\hline Factor & $\begin{array}{c}E G F R \\
\text { wild-type } \\
(\mathrm{n}=26)\end{array}$ & $\begin{array}{c}E G F R- \\
\text { mutated } \\
(\mathrm{n}=8)\end{array}$ & $p$-Value \\
\hline \multicolumn{4}{|l|}{ Clinical } \\
\hline \multicolumn{4}{|l|}{ Age, years } \\
\hline Mean (SD) & $60.0(10.3)$ & $61.1(18.5)$ & $0.826^{\mathrm{a}}$ \\
\hline \multicolumn{4}{|l|}{ Gender, $\mathrm{n}$} \\
\hline Male $(n=23)$ & 20 & 3 & $0.079^{b}$ \\
\hline Female $(\mathrm{n}=11)$ & 6 & 5 & \\
\hline \multicolumn{4}{|l|}{ Smoking history, $\mathrm{n}$} \\
\hline Never-smoker $(\mathrm{n}=9)$ & 3 & 6 & $0.001^{\mathrm{b}}$ \\
\hline Smoker $(n=25)$ & 23 & 2 & \\
\hline \multicolumn{4}{|l|}{ Pack year } \\
\hline Median (range) & $40(0-84)$ & $0(0-15)$ & $<0.001^{\mathrm{c}}$ \\
\hline \multicolumn{4}{|l|}{ Performance status, $\mathrm{n}$} \\
\hline$\leq 1(n=19)$ & 15 & 4 & $>0.99^{b}$ \\
\hline$\geq 2(n=15)$ & 11 & 4 & \\
\hline \multicolumn{4}{|c|}{$E G F R$ status in primary lung cancer, $\mathrm{n}$} \\
\hline Wild-type $(n=26)$ & 26 & 0 & $<0.001^{b}$ \\
\hline Mutant $(\mathrm{n}=8)$ & 0 & 8 & \\
\hline \multicolumn{4}{|l|}{ Radiological } \\
\hline \multicolumn{4}{|l|}{ Number of BMs, $n$} \\
\hline Single $(n=20)$ & 18 & 2 & $0.042^{\mathrm{b}}$ \\
\hline Multiple ( $n=14)$ & 8 & 6 & \\
\hline \multicolumn{4}{|l|}{ Size of the BMs, $\mathrm{cm}$} \\
\hline Mean (SD) & $3.6(1.2)$ & $3.4(1.4)$ & $0.675^{\mathrm{a}}$ \\
\hline \multicolumn{4}{|c|}{ Supratentorial vs. Infratentorial, $\mathrm{n}$} \\
\hline Supratentorial $(\mathrm{n}=29)$ & 21 & 8 & $0.309^{b}$ \\
\hline Infratentorial $(\mathrm{n}=5)$ & 5 & 0 & \\
\hline \multicolumn{4}{|c|}{ Cortico-medullary vs. Central, $\mathrm{n}$} \\
\hline Cortico-medullary $(\mathrm{n}=27)$ & 23 & 4 & $0.037^{\mathrm{b}}$ \\
\hline Central $(n=7)$ & 3 & 4 & \\
\hline
\end{tabular}

SD, Standard deviation. 'Student's $t$-test; btwo-sided Fisher's exact test; cMann-Whitney $U$-test.

adenocarcinoma, Togashi et al. reported that when patients with EGFR-mutated lung adenocarcinoma develop pulmonary metastases, they tend to be diffuse and random, which is in line with our findings (19). Given that central location of BMs may result in significant damage to the central nervous system, careful follow-up of patients with EGFR-mutated NSCLC may be necessary.

The present study is associated with several limitations. Firstly, this was a retrospective study investigating a very small cohort of patients from a single center. Indication for surgical resection of BMs is dependent on the size, location, and number of BMs, which is associated with selection bias. Thus, it is difficult to draw definitive conclusions. Secondly, although there is ample evidence that these radiological features are useful in predicting tumor characteristics, there 
are no criteria without exceptions (20). The EGFR status of each sample (primary and BMs) should be examined if the sample is available.

In conclusion, the EGFR-mutated BMs were associated with the higher frequencies of multiple metastases and their location in the central area of the brain in comparison to the non-EGFR-mutated BMs. Careful follow-up of patients with $E G F R$-mutated NSCLC may be necessary given the severe symptoms derived from multiple and centralised BMs. Further prospective studies investigating larger sample sizes are necessary to validate these findings.

\section{Conflicts of Interest}

All the Authors declare no conflicts of interest in regard to this study.

\section{References}

1 Torre LA, Bray F, Siegel RL, Ferlay J, Lortet-Tieulent J and Jemal A: Global cancer statistics, 2012. CA Cancer J Clin 65: 87-108, 2015.

2 Ettinger DS, Akerley W, Bepler G, Blum MG, Chang A, Cheney RT, Chirieac LR, D'Amico TA, Demmy TL, Ganti AK, Govindan R, Grannis FW Jr., Jahan T, Jahanzeb M, Johnson DH, Kessinger A, Komaki R, Kong FM, Kris MG, Krug LM, Le QT, Lennes IT, Martins R, O’Malley J, Osarogiagbon RU, Otterson GA, Patel JD, Pisters KM, Reckamp K, Riely GJ, Rohren E, Simon GR, Swanson SJ, Wood DE and Yang SC: Non-small cell lung cancer. J Natl Compr Canc Netw 8: 740-801, 2010.

3 Takada K, Toyokawa G, Shoji F, Okamoto T and Maehara Y: The significance of the PD-L1 expression in non-small-cell lung cancer: Trenchant double swords as predictive and prognostic markers. Clin Lung Cancer 19: 120-129, 2018.

4 Toyokawa G, Kozuma Y, Matsubara T, Haratake N, Takamori S, Akamine T, Takada K, Katsura M, Shoji F, Okamoto T and Maehara Y: Radiological features of the surgically resected small-sized small-cell lung cancer on computed tomography. Anticancer Res 37: 877-881, 2017.

5 Toyokawa G, Shimokawa M, Kozuma Y, Matsubara T, Haratake N, Takamori S, Akamine T, Takada K, Katsura M, Shoji F, Okamoto T and Maehara Y: Invasive features of small-sized lung adenocarcinoma adjoining emphysematous bullae. Eur $\mathbf{J}$ Cardiothorac Surg, 2017. doi: 10.1093/ejcts/ezx295. [Epub ahead of print]

6 Toyokawa G, Takada K, Okamoto T, Shimokawa M, Kozuma Y, Matsubara T, Haratake N, Takamori S, Akamine T, Katsura M, Shoji F, Oda Y and Maehara Y: Computed tomography features of lung adenocarcinomas with programmed death ligand 1 expression. Clin Lung Cancer 18: e375-e383, 2017.

7 Yamamoto S, Korn RL, Oklu R, Migdal C, Gotway MB, Weiss GJ, Iafrate AJ, Kim DW and Kuo MD: ALK molecular phenotype in non-small cell lung cancer: CT radiogenomic characterization. Radiology 272: 568-576, 2014.

8 Hasegawa M, Sakai F, Ishikawa R, Kimura F, Ishida H and Kobayashi K: CT Features of epidermal growth factor receptormutated adenocarcinoma of the lung: Comparison with nonmutated adenocarcinoma. J Thorac Oncol 11: 819-826, 2016.
9 Schouten LJ, Rutten J, Huveneers HA and Twijnstra A: Incidence of brain metastases in a cohort of patients with carcinoma of the breast, colon, kidney and lung and melanoma. Cancer 94: 2698-2705, 2002.

10 Barnholtz-Sloan JS, Sloan AE, Davis FG, Vigneau FD, Lai P and Sawaya RE: Incidence proportions of brain metastases in patients diagnosed (1973 to 2001) in the Metropolitan Detroit Cancer Surveillance System. J Clin Oncol 22: 2865-2872, 2004.

11 Preusser M, Winkler F, Valiente M, Manegold C, Moyal E, Widhalm G, Tonn JC and Zielinski C: Recent advances in the biology and treatment of brain metastases of non-small cell lung cancer: Summary of a multidisciplinary roundtable discussion. ESMO Open 3: e000262, 2018.

12 Patchell RA, Tibbs PA, Walsh JW, Dempsey RJ, Maruyama Y, Kryscio RJ, Markesbery WR, Macdonald JS and Young B: A randomized trial of surgery in the treatment of single metastases to the brain. N Engl J Med 322: 494-500, 1990.

13 Vecht CJ, Haaxma-Reiche H, Noordijk EM, Padberg GW, Voormolen JH, Hoekstra FH, Tans JT, Lambooij N, Metsaars JA, Wattendorff AR, Brand R and Hermans J: Treatment of single brain metastasis: Radiotherapy alone or combined with neurosurgery? Ann Neurol 33: 583-590, 1993.

14 Sherwood J, Dearden S, Ratcliffe M and Walker J: Mutation status concordance between primary lesions and metastatic sites of advanced non-small-cell lung cancer and the impact of mutation testing methodologies: a literature review. J Exp Clin Cancer Res 34: 92, 2015.

15 Park K and Goto K: A review of the benefit-risk profile of gefitinib in Asian patients with advanced non-small-cell lung cancer. Curr Med ResOpin 22: 561-573, 2006.

16 Delattre JY, Krol G, Thaler HT and Posner JB: Distribution of brain metastases. Arch Neurol 45: 741-744, 1988.

17 Hwang TL, Close TP, Grego JM, Brannon WL and Gonzales F: Predilection of brain metastasis in gray and white matter junction and vascular border zones. Cancer 77: 1551-1555, 1996.

18 Pekmezci M and Perry A: Neuropathology of brain metastases. Surg Neurol Int 4: S245-255, 2013.

19 Togashi Y, Masago K, Kubo T, Sakamori Y, Kim YH, Hatachi Y, Fukuhara A, Mio T, Togashi K and Mishima M: Association of diffuse, random pulmonary metastases, including miliary metastases, with epidermal growth factor receptor mutations in lung adenocarcinoma. Cancer 117: 819-825, 2011.

20 Takamori S, Yamaguchi M, Taguchi K, Edagawa M, Shimamatsu S, Toyozawa R, Nosaki K, Hirai F, Seto T, Takenoyama M and Ichinose Y: Uncommon features of surgically resected ALKpositive cavitary lung adenocarcinoma: a case report. Surg Case Rep 3: 46, 2017. 